\title{
VIRTUAL MUSEUMS AND THEIR PUBLIC PERCEPTION IN BOSNIA AND HERZEGOVINA
}

\author{
S. Rizvic $^{a, *}$, A. Sadzak ${ }^{a}$, B. Ramic-Brkic ${ }^{b}$, V. Hulusic ${ }^{b}$ \\ ${ }^{a}$ Faculty of Electrical Engineering, University of Sarajevo, \\ Zmaja od Bosne bb, 71000 Sarajevo, Bosnia and Herzegovina - (srizvic, asadzak)@etf.unsa.ba \\ ${ }^{b}$ International Digital Lab, WMG University of Warwick, Coventry, CV4 7A, UK - (b.ramic, v.hulusic)@ warwick.ac.uk
}

KEY WORDS: Virtual reality, virtual museums, cultural heritage

\begin{abstract}
:
Bosnia and Herzegovina always has been a place where the East meets the West. Over 1000 years, different cultures, religions and civilizations have left their remains in this small country in Western Balkans. Despite all wars and tragic destructions, today in the heart of Sarajevo one can find mosques, Catholic and Orthodox churches and Jewish synagogues next to each other and people of different nations and religions living together in mutual respect and friendship. Multiethnic spirit of Bosnia and Herzegovina lives through its cultural heritage. Therefore our task is to ensure its presentation and preservation using Information and Communications Technologies (ICT). So far researchers have achieved significant results by creating several virtual museums. In this paper we will present the Museum of Bosnian Traditional Objects, Digital Catalogue of Stecaks and the Virtual Museum of Sarajevo Assassination, giving an overview of the process of creating virtual environments from multiple data sources based on various 3D digitization technologies: some based on traditional 3D modeling, other based on laser scanning or photogrametric techniques.
\end{abstract}

\section{INTRODUCTION}

Bosnia and Herzegovina was always a place where the East meets the West. Over 1000 years, different cultures, religions and civilizations have left their remains in this small country inWestern Balkans. Despite all wars and tragic destructions, today in the heart of Sarajevo one can find mosques, Catholic and Orthodox churches and Jewish synagogues next to each other and people of different nations and religions living together in mutual respect and friendship. Multiethnic spirit of Bosnia and Herzegovina lives through its cultural heritage.

Therefore our task is to ensure its presentation and preservation using Information and Communications Technologies (ICT). So far researchers have achieved significant results by creating several virtual museums. In this paper we will present the Museum of Bosnian Traditional Objects, Digital Catalogue of Stecaks and the Virtual Museum of Sarajevo Assassination, giving an overview of the development process, techniques and technologies used in that process. Since virtual museums are quite a new form of cultural heritage presentation in Bosnia and Herzegovina, we made a survey on how different user groups, such as cultural heritage workers, museum curators and general public, appreciate this new concept. The feedback will confirm the credibility of our research and give us directions for future projects.

The paper is structured as follows: Section 2 presents the related work in virtual museums field, Sections 3-5 describe creation of the Museum of Bosnian Traditional Objects, Digital Catalogue of Stecaks and the Virtual Museum of Sarajevo Assassination, Section 6 offers the analysis of the users feedback and results of the survey we conducted. Finally, in Section 7 we summarize our experiences and conclude the paper with some directions for the future.

\subsection{Related work}

In the current situation of globalization, technological advancement, and population mobility, it becomes clear that the technology is changing cultures and communities (Avrami, 2000). Internet provides a low-cost and immediate means of transmitting museums information to people over great distances when access to museums can be difficult for some people due to, for example, high travel costs. The use of new technologies helps museums to reach a new learner community, breaking through barriers of geography and time.

The development of virtual museums started almost two decades ago. Initially museums provided only a simple hyper-link text with graphics which contained the basic information about the museum. However, museums began to realize the potential of new technologies for the development of various contents and services for their visitors such as advanced use of multimedia, clips, animations, 3D collections and audio. These could either be systems for interactively viewing individual 3D objects (VRML based, Cult3D, etc.), pseudo-3D systems for displaying interactively controlled panoramic views (IPIX, QTVR) or mechanisms for viewing static stereo images of $3 \mathrm{~d}$ models (Lepouras et al., 2001). In research by Kravchyna and Hastings in 2002 on different user groups and their information needs, it was reported that $68 \%$ of users are seeking information about current exhibits. Virtual visitors $(63 \%)$ particularly like the capability to browse the collection database and to locate supplementary descriptive information (Kravchyna, 2004).

Some of the pioneering examples of virtual museums are the Uffizi (Florence) (The Uffizi (Florence), n.d.), the Louvre (Louvre, 2005), the National Gallery (London) (The National Gallery (London), 2000-2011) and the Metropolitan Museum (New York) (Metropolitan Museum, 2000). In the case of Uffizi Museum, an online version of the entire museum with simple Quick Time VR model of each room was created (Veltman, 2002). Virtual reality technologies indeed promise to offer a vivid, enjoyable experience to museum visitors and above all, represent a powerful medium for displaying museum artifacts. This is particularly important since most museums do not have adequate resources for storing and preserving various collections and artifacts. Furthermore, in the real museums, the interaction of visitors with exhibited artifacts is usually limited and restricted, i.e., they cannot look at the object from all angles or take photos with camera flash on. 
Another example of a simple online museum that also uses QuickTime Virtual Reality (QTVR) segments to enrich the presentation of the materials, is the Virtual Tour of the National Museum of the American Indian Exhibitions Creation's Journey and All Roads are Good (Jones and Christal, 2002). The students from Indian schools participated actively in the creation of the content. Similarly, in 2005 the Virtual BH National Museum project has been implemented as a result of students research work on the Computer graphics Course at the Faculty of Electrical Engineering in Sarajevo (Deljkic et al., 2006). A special collection of interactive exhibits (VRML, QT Panoramas, and galleries) was produced and distributed via the Web.

A more sophisticated internet presentation that uses advanced web browser plug-ins to create an advanced multimedia interface is the Virtual Smithsonian. The Virtual Smithsonian highlights over 360 artifacts along with a virtual tour of the Castle. The online web-based exhibits are composed of high resolution images, video and audio clips, and artifacts that rotate in 3D (QTVR) and morph into other artifacts (Press, 1990, Jones and Christal, 2002). Furthermore, the Gifu Art Museum in Japan has an HDTV system for viewing its collection. More examples of similar systems can be seen at the web sites of the Tower of Pisa (The Tower of Pisa, n.d.) and Hermitage Museum (Hermitage Museum, 2006).

In the past years, various projects have been proposed with the goal to combine digital objects from museum collections all over the world. The goal of this type of virtual museum is to provide not only information about the institutions' collection, but to link it to the other digital collections. This way, the created digital collections have no counterparts in the real world. This represents the implementation of Andre Malraux's vision of the "museum without walls" (Schweibenz, 2004). One of the most impressive projects in this context is the Virtual Museum of Canada (The Virtual Museum of Canada, n.d.), which includes materials from 710 member museums and has exhibition materials in three languages.

The Europeana group comprises a number of projects run by different cultural heritage institutions and in a way also represents an implementation of Andre Malraux's vision. ATHENA as one of the Europeana current projects represents an aggregator and its main goal is to encourage the participation of museums to bring their content more easily to a single location, Europeana.eu. The goal of this project and also an expected result is to enrich the content using semantic web technologies, multilingual thesauri, other language resources and a data model optimized for the integration of museum content into Europeana (ATHENA, 2008).

One of the forthcoming Europeana projects is CARARE, funded under the European Commission's ICT Policy Support Programme, whose goal is to make archaeology and architectural heritage content available through Europeana. CARARE is designed to involve and support Europe's network of heritage agencies and organisations, archaeological museums and research institutions and specialist digital archives. Its aim is to establish a point of access to 3D/VR objects and develop a sustainable CARARE network. Two millions items will be made available throughout Europe within the framework of the project. That number is considerable when compared with the four million currently offered by the European web site. The objects will be referenced geographically, enabling the production of maps for use in commerce, tourism or research (CARARE, 2010).

Damala et al. created a prototype of a virtual mobile multimedia museum guide for few artifacts in the Museum of Fine Arts in Rennes, France (Damala et al., 2008). They used text, audio, video, slideshows as well as $2 \mathrm{D}$ and $3 \mathrm{D}$ digital overlays. The interface design was very simple with a three layer navigation scheme employed. Once the particular painting is detected, user only has a predefined number of options to choose from. Users are given a chance to pause, forward or go back in the 2D and 3D multimedia presentations.

Two main difficulties that museums are facing are the difficulty of creating virtual content and the expense of such technology. The second problem may be resolved by technology improvement. However, for the technology to be widely acceptable and used, museums need efficient, cost effective and above all simple methods of creating such $3 \mathrm{D}$ content. Therefore, research community in the field is trying to achieve this through various projects, such as SCULPTEUR (SCULPTEUR, 2003), 3D Murale (3D Murale, 2003), ARCO (ARCO, 2003) which are funded by the Commission of the European Community within the Fifth Framework in order to help and advent this area. However, despite the difficulties with which museums are faced, Tsapatori showed that in 2003, around 35\% of museums in Europe have already started and by today completed developments with some form of 3D presentation of objects (Tsapatori, 2003). In USA, more than $30 \%$ of museums in 2004 had digitization activities while $18 \%$ indicated that they plan digitization activities in 2005 (Kravchyna, 2004).

\section{MUSEUM OF BOSNIAN TRADITIONAL OBJECTS}

Faculty of Electrical Engineering Sarajevo, as a part of the Sarajevo Graphics Group, works through its Computer Graphics course and research on the projects related to virtual reconstruction, digitization and multimedia presentation of tangible and intangible cultural heritage (Buza et al., 2008, Hulusic, 2007, Jovisic and Rizvic, 2008, Karkin and Rizvic, 2008, Virtual National Museum of Bosnia and Herzegovina, 2006, Rizvic et al., 2005, Rizvic and Sadzak, 2008, Zukic and Rizvic, 2006). At the basic Computer Graphics course taught on the 3rd year of Computer Science undergraduate studies, we decided to organize the lab projects in order to create a digital collection of the selected exhibits from the Museum of City of Sarajevo. The product of this work is the Museum of Bosnian Traditional Objects.

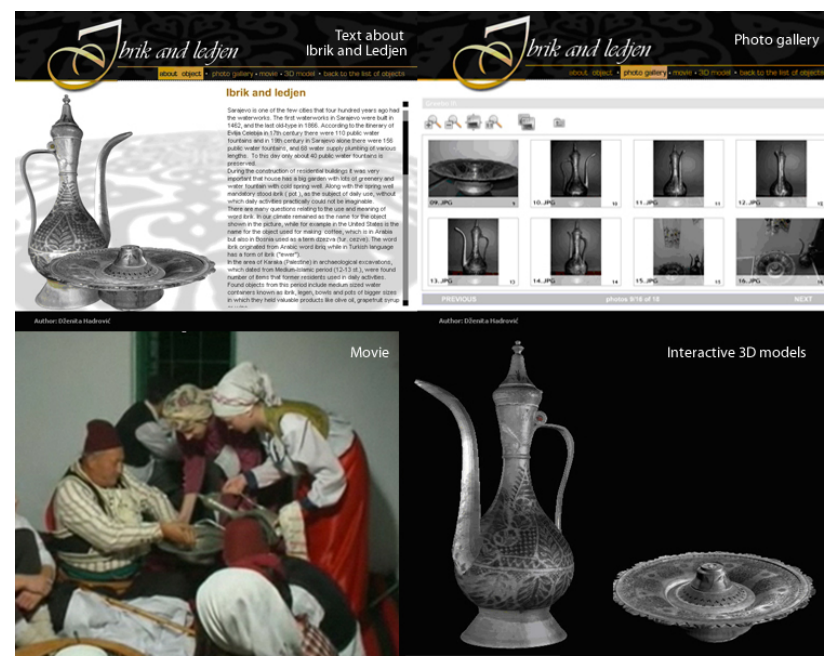

Figure 1: Presentation of Ibrik and Ledjen. Left to right: text, photos (top); movie, interactive 3D models (bottom).

Museum curators have selected various objects related to the life of citizens, belonging to different traditions and religions and different periods of time. The main criterion for this selection was not so much related to the history of the objects, but more 
to their geometry. The virtual museum contains objects from medieval Muslim households, Jewish religious objects, exhibits from the Austrian Hungarian period, along with the archaeological findings from the Iron Age and Roman Period. Every object is presented through a text with the basic historical information, a gallery of photos, a movie and an interactive 3D model. The text gives some necessary information about the object and its history. Gallery of photos is created to enable the user to compare the real appearance of the object with its interactive 3D model. The movie gives more details about the object and shows the purpose for which the object was used, for many objects do not obviously unravel that information just by their appearance. Additionally, the interactive 3D model provides a visitor with a possibility of moving objects and turning them around, which is not possible in the real museum, where the exhibits are usually placed in the glass protected shelves and touching them is strictly prohibited.

The digital content created for every exhibit is shown in Figure 1, using the example of the Ibrik and Ledjen exhibit. Ibrik is a traditional Bosnian pot for water, usually hand carved in copper with beautiful floral and geometric ornaments. Ledjen serves as a movable basin for water during washing hands or face.

All digital content is organized in a web presentation (Virtual Museum of Bosnian Traditional Objects, 2009), starting from the home page, where the visitor chooses the language, enters into the first virtual environment of the museum and moves around, viewing the panels on the virtual walls which represent the objects. Clicking on each panel opens a new window with a digital content related to the particular virtual exhibit. The movies are presented in the Flash format and the interactive 3D models in VRML. For users who are not comfortable with browsing the central virtual environment in search for the objects, we created a list view with links to all the objects by their names. Through this project our students gained the knowledge of the basics of graphics design, composition and layout, film language grammar, 3D modeling techniques and web $3 \mathrm{D}$ technologies. The project is done gratis for the Museum of Sarajevo to introduce them with the potential of computer graphics in digital presentation of cultural heritage. More details about this project are presented in (Rizvic and Sadzak, 2010).

\section{DIGITAL CATALOGUE OF STECAKS}

The best known, and certainly the most valuable monuments of medieval art in Bosnia and Herzegovina are Stecaks. Stecaks are monumental gravestones, usually stone monoliths of varying shapes and sizes. There are about 60.000 tombstones organized in large necropolises all over Bosnia and Herzegovina.

The Stecak necropolises are a mysterious aspect of Bosnia and Herzegovina history. The most intriguing are their origins, to whom they belonged, who was buried under them, as well as engraved symbols, and mystic messages on them. The National Museum of Bosnia and Herzegovina has a rich collection of Stecaks placed in front of the main entrance and in the botanical garden. The Digital Catalogue of Stecaks (Figure 2) is a virtual representation of that collection, created by the students and staff of the Faculty of Electrical Engineering in Sarajevo (Digital Catalogue of Stecaks, 2009).

During the course in Numeric Graphics and Animation, taught on the first year of Masters Studies at the Faculty of Electrical Engineering in Sarajevo, the students learn photogrammetric 3D modeling using Photomodeler software. This interactive tool allows creation of a geometric model of the object based on a set of photographs. In order to develop the 3D models further and to make

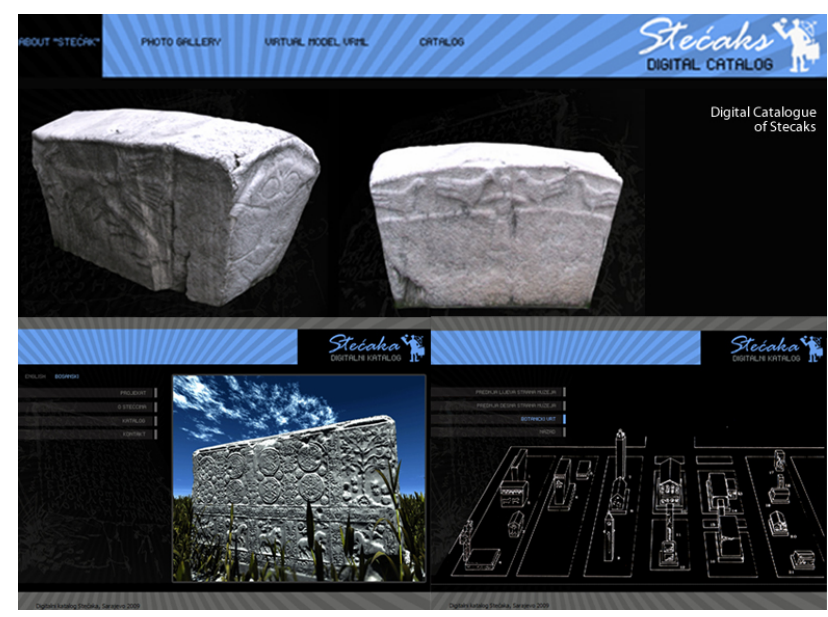

Figure 2: Digital Catalogue of Stecaks, home page. Bottom left: stecaks in botanical garden of the National Museum. Bottom right: Virtual exhibit stecak from Cerin near Citluk.

them more realistic, in addition to this modeling technique, the students used 3ds max modifiers (Radosevic and Rizvic, 2010b).

Each student had a task to model one of the Stecaks from the museum collection. The final product is an interactive digital catalog in the form of schematic description of the exhibitions (Figure 2, bottom left). By clicking on the specific object the visitor is provided with its website (Figure 2, bottom right), which contains historical data, gallery of photos and a 3D model, which can be explored in 3D space by using an adequate player.

This interactive catalog is also delivered in the DVD form, which may be distributed to the visitors of the Museum as a souvenir. The application is planned to be installed on a touch screen panel in the Museum, and is already online on the Museum's website.

\section{VIRTUAL MUSEUM OF SARAJEVO ASSASSINATION}

Museum of City of Sarajevo 1878-1918 houses several permanent exhibits related to the period of Austro-Hungarian rule in Bosnia and Herzegovina with particular focus on 28th of June, 1914, the day when the throne of Austria-Hungary Archduke Franz Ferdinand and his wife Sophie were assassinated in Sarajevo. This event, also known as "Sarajevo Assassination", triggered the onset of the First World War. The aim of the Virtual Museum of the Sarajevo Assassination two-stage project is to launch the process of digitalising the collections of the Museum Sarajevo 1878-1918, particularly those related to the Sarajevo Assassination (Virtual Museum of the Sarajevo Assassination, 2010). The first, implemented stage of the project includes:

1. Interactive 3D model of museum environment and the place of assassination, Figure 3, top left;

2. Interactive $3 \mathrm{D}$ model of the memorial to Franz Ferdinand and Sophie which was originally located in front of the building, and removed in 1919. The memorial model was created using a combination of laser scanning and 3D modelling (Radosevic and Rizvic, 2010a);

3. Panoramic view of museum exhibition. Interactive 360-degree panoramic photo of the central exhibition room was taken with a Spheron camera available by the Visualisation Group, University of Warwick, United Kingdom (Visualization Group, University of Warwick, n.d.); 


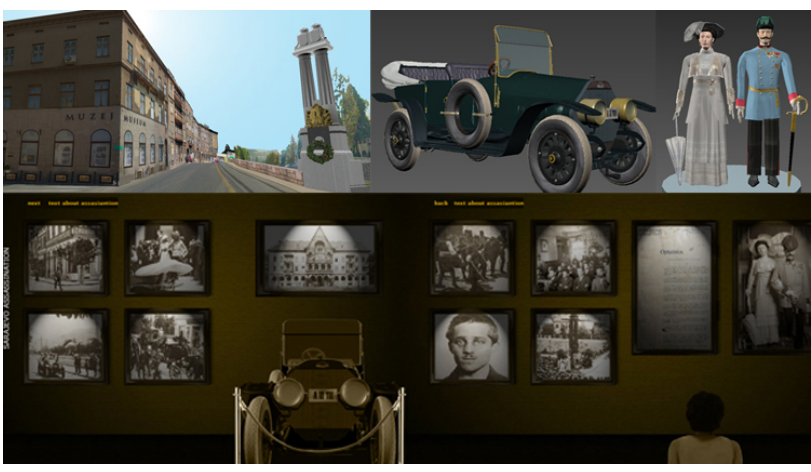

Figure 3: Top left:The model of the museum environment and the place of assassination. Top right: Interactive 3D models of the statues of Ferdinand and Sophie, and the car that drove them on the day of the assassination. Bottom: The virtual photo exhibition representing the event chronologically.

4. Interactive 3D model of the car that Archduke Franz Ferdinand was riding in when he was assassinated Figure 3, top right;

5. Interactive 3D statues of Franz Ferdinand and Sophie Chotek (Rizvic and Krezic, 2010);

6. Virtual photo exhibition presenting the assassination event chronologically. A click on individual exhibits opens galleries presenting photos, models and information on places and events. Figure 3, bottom;

7. Inserts from "Sarajevo assassination" movie, directed by Veljko Bulajic in1975.

The second phase should include digitalisation of the entire collection of the 1878-1918 collection of the Museum, an animated reconstruction of the assassination itself, as well as introduction of virtual guides and digital content, allowing users to explore it using augmented reality on their mobile devices. Souvenirs are also to be produced, based on prototypes of digitalised exhibits made using 3D printing.

\section{FEEDBACK}

Virtual museums have become a common practice and a complementary form of historical artifacts representation. However, there is still no evidence of how cultural heritage institutions and general public appreciate this form of presentation. Therefore, two surveys have been conducted in order to get a feedback from both museum curators and general public. The results of the survey can be used to improve current and create new virtual museums, not only in Bosnia and Herzegovina, but anywhere, where this form of cultural heritage representation is needed.

\subsection{Feedback from museum curators and cultural heritage institutions}

Museum curators are content specialists, responsible for the exhibits and collections setups in a museum. They are in charge of collecting and organizing artifacts, conducting research and taking care and track of the objects. Therefore, the creating of the virtual museums has to be closely coordinated with this group of people.
Upon the completion of the projects of virtual museums creation, they were presented in the actual museums in front of the institution employees and a limited number of general public. However, it was not possible to conduct a survey and get some feedback on the spot.

The survey has been made afterwards in three museums in Sarajevo: Museum of City of Sarajevo, National Museum of Bosnia and Herzegovina and Historical Museum of Bosnia and Herzegovina. First two museums have one or more virtual museums. Namely, the Museum of City of Sarajevo has the virtual museum of Bosnian traditional objects and the virtual museum of the Sarajevo Assassination. The National Museum of Bosnia and Herzegovina has the Digital Catalogue of Stecaks. The Historical Museum still has no virtual museums.

In the survey, 25 curators participated from these three museums. The first question in the questionnaire was if the museum, where the curator works, has its virtual edition. In the Museum of City of Sarajevo one out of five curators was not aware that the institution has the virtual museums. Other four curators knew about the museums and confirmed that they had visited them. The response to the second question was highly positive, see Table 1 .

In the National Museum we surveyed 13 curators. Rather shockingly, only one of them knew about the virtual museum (Digital Catalogue of Stecaks). The person had a positive response on all given answers (as in Table 1). All 7 curators from the historical Museum confirmed that their museum has no virtual museums, but that they would like to have one.

In all three museums, we have found a considerably similar pattern in the responses of the curators to the following questions: Suggestions and recommendations for the improvement of the existing virtual museums; Ideas and suggestions for the creations of the new virtual museums; General opinion of the virtual museums. They had a positive opinion of virtual museums in general. However, they thought virtual museums cannot replace the real ones but rather promote them and attract potential visitors to real museums. Therefore, some of them think that virtual museums should not contain too many details, but rather just a brief description of what can be seen in the real museum. Most of them agreed that each museum should have its virtual museum(s). Some of them suggested that each exhibition should have its own virtual museum. The curators also wrote that virtual museums are useful for disabled people, remote visitors and for preservation of the cultural heritage. The last one is extremely important as many objects seem to deteriorate and are endangered to be completely destroyed and lost.

The curators gave some interesting ideas for creation of some new virtual museums. Some of them are: virtual museum of flora and vegetation; virtual museum of minerals and rocks; virtual museum of the "life and culture" exhibition; virtual museum of the "life of the mammoths" exhibition; virtual museum of the medieval knights, including knight tournaments, balls and burial customs.

\subsection{Feedback from general public}

The questionnaire for general public differed from the one used for the curators. We surveyed 79 volunteers, aging from 12 to 60 , with an average of 33.5. There were 63 Bosnian and 13 foreign participants. All participants use computers on a regular basis and most of them use internet.

The survey results showed that the participants mostly expected to discover what they can see in the real museum. They also 


\begin{tabular}{|c|l|r|}
\hline \multicolumn{3}{|l|}{ Your opinion of the virtual museum(s) in your institution } \\
\hline a & Using the virtual museum is straightforward & $60 \%$ \\
\hline b & Virtual museum contains enough information about the artifacts & $100 \%$ \\
\hline c & The artifacts are displayed with enough details & $100 \%$ \\
\hline d & Movement through the virtual museum is straightforward & $100 \%$ \\
\hline e & The design of the virtual museum is attractive to a visitor & $100 \%$ \\
\hline f & A visit to the virtual museum can attract a visitor to the real museum & $100 \%$ \\
\hline
\end{tabular}

Table 1: The percentage of the positive responses to the given answers by the museum curators who claimed the existence of the virtual museum within their institution

wanted to gain some knowledge about the artifacts, which $84.4 \%$ claimed they actually did. About $70 \%$ of participants found the navigation as straightforward and were happy about the virtual museum and object appearance. However, only $36.4 \%$ felt as they were present in the real museum. Similarly to the response of the museum curators, general public's opinion of virtual museums is positive. They liked the idea and more than half think that each museum should have its virtual edition. The most expected type of multimedia was 3D content, images and video descriptions respectively.

A major drawback of the virtual museums was the software requirement. Since 3D models were interactively presented in Virtual Reality Modeling Language (VRML) format, a special software for displaying the content is required. Although it was clearly specified on the website of each virtual museum, a few participants did not manage or did not want to install it. Another problem with VRML, which was pointed out by one participant, can be the file size. The 3D models used in these projects were carefully optimized, and the possible reason of the extensive loading time is the speed and bandwidth of the user's internet connection. Additionally, several participants suggested to simplify the navigation. Navigation in VRML is standardized, and therefore the only way to improve it is to make the environment (virtual model) more intuitive by adding some salient objects and colors, road signs or similar dummy objects.

As opposed to the museum curators, the general public opinion was that there should be more descriptions and information about individual objects. Another thing, mentioned by many participants, is that there should be an interactive map showing how to get to the real museum. Additional results with percentages of positive answers from the questionnaire are given in Table 2.

\section{CONCLUSION}

In this paper we presented three virtual museum projects and the feedback of museum curators and general public about these projects. There are few major considerations important for understanding the feedback of the museum curators. Firstly, due to the tragic war events in Bosnia and Herzegovina, the status of the state museums is still not resolved. This is the reason of their eminently difficult financial situation, in which the institutions barely survive, having problems with the basic funding, such as staff salaries and maintenance of the buildings. Therefore, the museum employees show considerably low level of enthusiasm and no motivation for creating virtual museums or any other form of technological improvement. Furthermore, there is no single authority, including their management, who could push the museum staff forward in this direction. Therefore, the created projects are a product of enthusiastic group of researchers and few individuals.

Secondly, the museum curators consider that virtual museums should be just a brief description of the museum content, possibly because they see virtual museums as a threat to real ones.
However, this should not be the case, since virtual museums play a major role in their availability to a remote audience, particularly to potential visitors who cannot afford to visit a real museum.

Finally, the museum curators should be aware that virtual museums are an excellent form of cultural heritage preservation using a digital media - an everlasting format. Many museums face a problem where whole collections of artifacts are endangered to perish. One such example is the butterfly collection in the National Museum of Bosnian and Herzegovina, which is considered to be one of the biggest in Europe.

The results of the conducted survey will be an important guideline for our future projects. We shall try to find a funding scheme for training museum curators in new technologies and development of the new virtual museum projects. A significant target group will be the elementary and high school children, who can visit virtual museums through Internet in their classrooms, learning about tradition and cultural heritage without the expense of physical travelling. We shall improve the performance of our virtual environments, making them more user friendly and faster. Together with cultural heritage workers we plan to introduce virtual museums as an efficient method for preservation and promotion of our cultural heritage. Moreover, by communicating with the related institutions from around the Europe, we recognized similar problems and comparable reasoning of the museum curators. Therefore, this paper might be a guideline for other museums and similar institutions, in a process of digitization and virtual museum creation.

\section{REFERENCES}

3D Murale, 2003. http://www.dea.brunel.ac.uk/ project/murale/ (accessed 31 Jan. 2011).

ARCO, 2003. http://www . arco-web.org/ (accessed 31 Jan. 2011).

ATHENA, 2008. http://www . athenaeurope.org/ (accessed 31 Jan. 2011).

Avrami, E., 2000. Values and heritage conservation. GCI Newsletter.

Buza, E., Sadzak, A., Rizvic, S. and Avdagic, Z., 2008. Project "virtual sarajevo". In: International Symposium on Digitalization of Cultural Heritage in Bosnia and Herzegovina.

CARARE, 2010. http://www. carare.eu/(accessed 31 Jan. 2011).

Damala, A., Cubaud, P., Bationo, A., Houlier, P. and Marchal, I., 2008. Bridging the gap between the digital and the physical: design and evaluation of a mobile augmented reality guide for the museum visit. In: DIMEA '08: Proceedings of the 3rd international conference on Digital Interactive Media in Entertainment and Arts, pp. 120-127. 


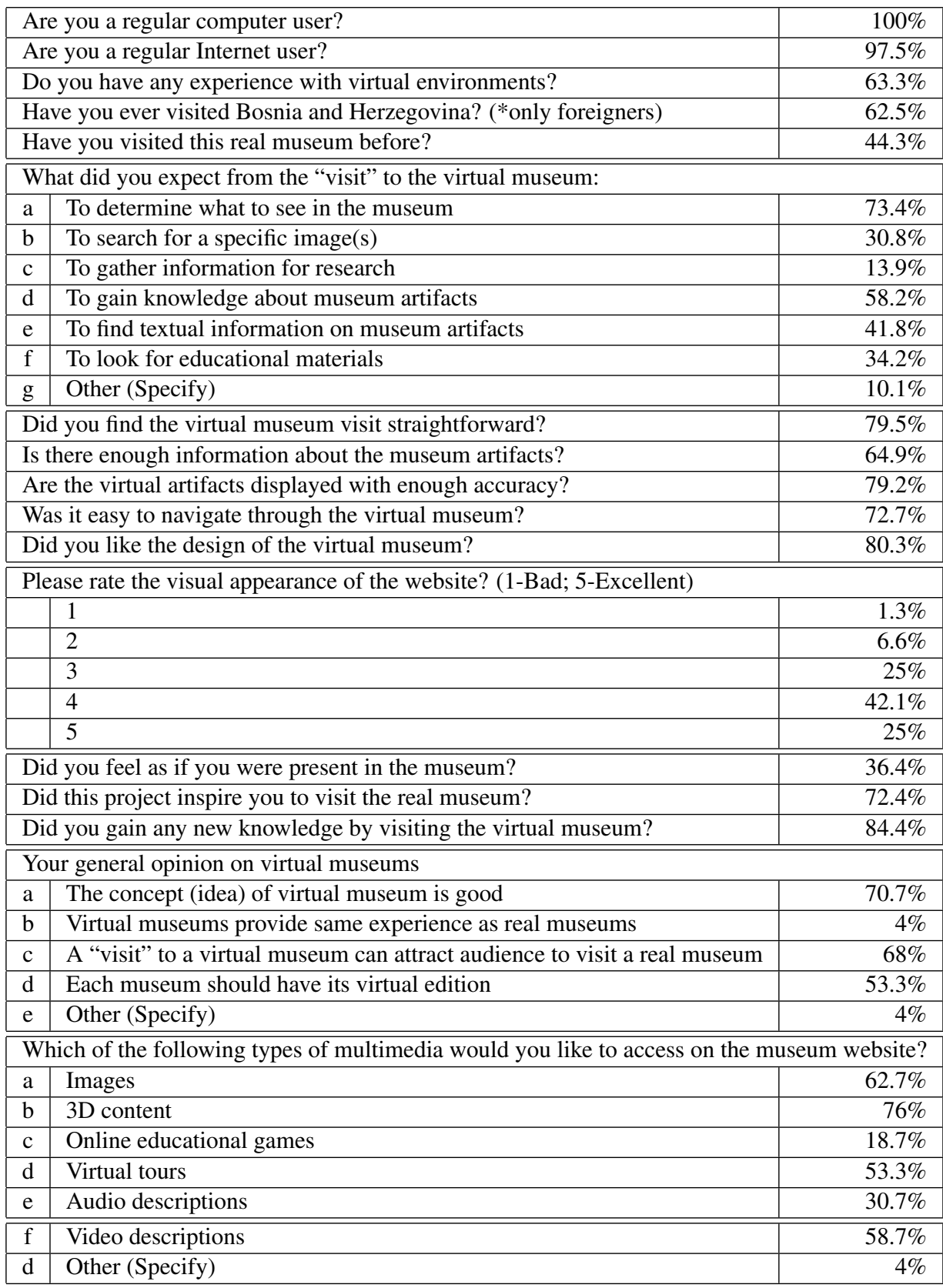

Table 2: The percentage of the positive responses given by the general public 
Deljkic, E., Jovicic, J., Badnjevic, N. and Biser, S., 2006. Virtual bosnia and herzegovina national museum. In: Proceedings of Central European Seminar on Computer Graphics for students, CESCG.

Digital Catalogue of Stecaks, 2009. http://h.etf .unsa.ba/ dig-katalog-stecaka/ (accessed 31 Jan. 2011).

Hermitage Museum, 2006. http://www.hermitage.ru/ (accessed 31 Jan. 2011)

Hulusic, V., 2007. Optimization treshold in sarajevo city hall virtual model for efficient web presentation. In: Proceedings of Central European Seminar on Computer Graphics for students, CESCG, Bratislava, Slovakia.

Jones, G. and Christal, M., 2002. The future of virtual museums: On-line, immersive, $3 \mathrm{~d}$ environments. Technical report, Created Realities Group.

Jovisic, V. and Rizvic, S., 2008. Photorealistic reconstruction and multimedia presentation of the medieval fortress in travnik. In: Proceedings of SEEDI, Belgrade, Serbia.

Karkin, Z. and Rizvic, S., 2008. Virtuelna 3d rekonstrukcija crkve svete trojice u mostaru. In: International Symposium on Digitalization of Cultural Heritage in Bosnia and Herzegovina.

Kravchyna, V., 2004. Information Needs of Art Museum Visitors: Real and Virtual. PhD thesis, University of North Texas.

Lepouras, G., Charitos, D., Vassilakis, C., Charissi, A. and Halatsi, L., 2001. Building a vr - museum an a museum. In: Proceedings of Third International Virtual Rality Conference, VRIC2001, Laval, France, pp. 16-20.

Louvre, 2005. http://www.louvre.fr/ (accessed 31 Jan. 2011).

Metropolitan Museum, 2000. http://www.metmuseum. org/(accessed 31 Jan. 2011). (accessed 31 Jan. 2011).

The National Gallery (London), 2000-2011. http://www . nationalgallery.org.uk (accessed 31 Jan. 2011).

Press, L., 1990. Compuvision or teleputer? Communications of the Association for Computing Machinery 33(9), pp. 29-36.

Radosevic, G. and Rizvic, S., 2010a. From laser scan to interactive 3d. In: II International Symposium on Digitalization of Cultural Heritage of Bosnia and Herzegovina.

Radosevic, G. and Rizvic, S., 2010b. Laser scanning versus photogrammetry combined with manual post-modeling in stecak digitization. In: Proceedings of Central European Seminar on Computer Graphics for students, CESCG, Bratislava, Slovakia.

Rizvic, S. and Krezic, A., 2010. Interactive models of ferdinand and sophie. In: II International Symposium on Digitalization of Cultural Heritage of Bosnia and Herzegovina.

Rizvic, S. and Sadzak, A., 2008. Digital storytelling - representation of bosnian intangible heritage in the virtual sarajevo project. In: International Symposium on Virtual Reality, Archaeology and Cultural Heritage (VAST 2008), Braga, Portugal.

Rizvic, S. and Sadzak, A., 2010. Virtual museum of bosnian traditional objects. In: Proceedings of SEEDI, Sarajevo.

Rizvic, S., Sadzak, A. and Avdagic, Z., 2005. The techniques of virtual $3 \mathrm{~d}$ reconstruction of heritage sites in bosnia and herzegovina. In: Proceedings of ICAT'05: Information, Communication \& Automation Technologies, sarajevo.
Schweibenz, W., 2004. The development of virtual museums. Technical report, Adjunct Faculty, Department of Information Science, University of Saarland, Germany.

SCULPTEUR, 2003. org/(accessed 31 Jan. 2011).

http://www. sculpteurweb.

The Tower of Pisa, n.d. http://www.italyguides.it/us/ pisa/pisa_italy.htm (accessed 31 Jan. 2011).

Tsapatori, M., 2003. Orion research roadmap for the european archaeological museums' sector (final edition).

The Uffizi (Florence), n.d. http://musa.uffizi.firenze. it/ (accessed Sep. 2010).

Veltman, K. H., 2002. Challenges of virtual and digital culture. In: Congreso Internacional Culturtec 2002, III European Conference: Employment and Cultural Heritage, Economic Development and New Technologies in the Information and Knowledge Society, Madrid.

Virtual Museum of Bosnian Traditional Objects, 2009. http: // www.muzejsarajeva.ba/btp/content/submenu.htm/ (accessed 31 Jan. 2011).

The Virtual Museum of Canada, n.d. http://www. museevirtuel-virtualmuseum.ca/ (accessed 31 Jan. 2011).

Virtual Museum of the Sarajevo Assassination, 2010. http:// h. etf .unsa.ba/vmuzej-atentata (accessed 31 Jan. 2011).

Virtual National Museum of Bosnia and Herzegovina, 2006. http://projects.etf. unsa.ba/ vmuzej/ (accessed 31 Jan. 2011).

Visualization Group, University of Warwick, n.d. http:// digital.warwick.ac.uk/Visualisation (accessed 31 Jan. 2011).

Zukic, A. and Rizvic, S., 2006. Virtuelna rekonstrukcija i web prezentacija isa-begove tekije na bentbasi. In: Proceedings of BIHTEL '06, Sarajevo. 